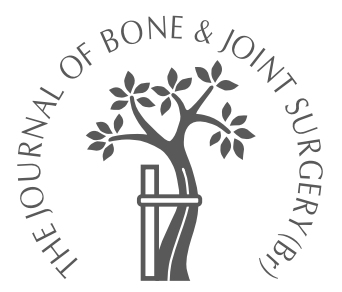

H. Tsuchiya,

S. L. Wan,

K. Sakayama,

N. Yamamoto,

H. Nishida,

K. Tomita

From Kanazawa

University,

Kanazawa, Japan

H. Tsuchiya, MD, PhD Associate Professor N. Yamamoto, MD, PhD, Assistant Professor

H. Nishida, MD,

Postdoctoral Fellow

K. Tomita, MD, PhD,

Professor and Chairman

Department of Orthopaedic

Surgery, Graduate School of

Medical Science, Kanazawa

University, 13-1 Takara-

machi, Kanazawa 920-8641,

Japan.

S. L. Wan, MD, PhD

Associate Professor

Department of Orthopaedic

Surgery, Sir Run Run Shaw

Hospital, School of Medicine,

Zhejiang University, 3 Qing

Chun Road East, Hangzhou

310016, People's Republic of China.

K. Sakayama, MD, PhD, Assistant Professor

Department of Orthopaedic

Surgery, Ehime University

School of Medicine,

Shitsukawa, Shigenobu-cho

Onsengun, Ehime 791-0295,

Japan.

Correspondence should be sent to Dr H. Tsuchiya; e-mail: tsuchi@med.kanazawa-u.

ac.jp

(C)2005 British Editorial

Society of Bone and

Joint Surgery

doi:10.1302/0301-620X.87B2.

$15325 \$ 2.00$

$J$ Bone Joint Surg [Br]

2005;87-B:218-25.

Received 20 January 2004

Accepted after revision

27 May 2004

\title{
Reconstruction using an autograft containing tumour treated by liquid nitrogen
}

We describe a method of reconstruction using tumour-bearing autograft treated by liquid nitrogen in 28 patients. The operative technique consisted of en bloc excision of the tumour, removal of soft tissue, curettage of the tumour, drilling and preparation for internal fixation or prosthetic replacement before incubation for $\mathbf{2 0}$ minutes in liquid nitrogen, thawing at room temperature for $\mathbf{1 5}$ minutes, thawing in distilled water for ten minutes, and internal fixation with an intramedullary nail, plate or composite use of prosthetic replacement. Bone graft or cement was used to augment bone strength when necessary.

The limb function was rated as excellent in 20 patients $(71.4 \%)$, good in three $(10.7 \%)$, fair in three $(\mathbf{1 0 . 7} \%)$, and poor in two $(\mathbf{7 . 1 \% )}$. At the final follow-up six patients had died at a mean of 19.8 months after the operation, while 21 remained free from disease with a mean follow-up of $\mathbf{2 8 . 1}$ months (10 to 54). One patient is alive with disease. Bony union was seen at a mean of 6.7 months after the operation in 26 patients. Complications were encountered in seven patients, including three deep infections, two fractures, and two local recurrences. All were managed successfully. Our results suggest that this is a simple and effective method of biological reconstruction.

Advances in diagnostic imaging, neoadjuvant chemotherapy, and operative technique have made it possible to treat malignant tumours of bone and soft tissue by limb salvage. With multidisciplinary treatment, such techniques produce a functional and durable limb without reducing the long-term results. All the established methods of reconstruction such as the use of massive prostheses, allografts, combinations of allografts and prostheses or with bone cement have made limb salvage possible. Endoprosthetic replacement after excision of the tumour can provide excellent results more quickly than with other methods. In a large series $^{1}$ the probability of a patient avoiding aseptic loosening for five years was $93.8 \%$ for a proximal femoral replacement, $67.4 \%$ for a distal femoral prosthesis and $58 \%$ for a proximal tibial implant. The survival rates for reconstructions around the knee now exceed $85 \%$ at five years. ${ }^{2}$ Survival at ten years after massive prosthetic replacement of the distal femur is approximately $50 \%{ }^{3}$ while that of prostheses in the proximal humerus with mechanical failure as the end-point is $86.5 \%$ at 20 years. ${ }^{4}$ Development of extendible prostheses now allows their use in growing children. ${ }^{5-7}$

Biological reconstruction may employ either living or dead bone. Recently, epiphyseal pres- ervation and reconstruction with distraction osteogenesis have provided excellent function of the limb in selected cases. ${ }^{8-10}$ Anatomical remodelling of the hip reconstructed with a massive allograft combined with a vascularised fibular transplant has been achieved in a child. ${ }^{11}$ Allografts are an example of biological reconstruction utilising dead bone. Mankin ${ }^{12}$ found that $77 \%$ of the allografts were still functional and competent. The best results were obtained with intercalary grafts while the poorest were with allograft arthrodesis. Fracture and nonunion reduce the rate of success. The addition of intramedullary cement to large-segment allografts improves their survival by decreasing the risk of fracture. ${ }^{13}$ Allograft prosthetic composite arthroplasty has also been used to solve the problem of degenerative changes occurring in osteoarticular allografts. $^{14}$

Allograft is difficult to obtain in some Asian countries, especially in Japan, for socioreligious reasons. Therefore, recycling of bone has been widely used. Several methods have been developed to re-use the resected bone for reconstruction, including irradiation, ${ }^{15,16}$ autoclaving $^{17,18}$ and pasteurisation. ${ }^{19,20}$ These methods require special equipment and strict thermal control. Heat treatment causes weak- 
Table I. Details of the patients who had reconstruction with a tumour-bearing massive frozen autograft treated by liquid nitrogen

\begin{tabular}{|c|c|c|c|c|c|c|c|c|c|c|c|}
\hline Case & $\begin{array}{l}\text { Gender } \\
\text { and age } \\
\text { (yrs) }\end{array}$ & Site* & Staget & Diagnosis & $\begin{array}{l}\text { Reconstruction } \\
\text { method } ¥\end{array}$ & Chemotherapy & $\begin{array}{l}\text { Bony } \\
\text { union } \\
\text { (mths) }\end{array}$ & Function§ & Complications & $\begin{array}{l}\text { Follow-up } \\
\text { (mths) }\end{array}$ & Outcomeף \\
\hline 1 & $\mathrm{M} / 17$ & Femur(d) & M1 & Osteosarcoma & T1-A, M+Plate & $\mathrm{K} 2$ & - & $E$ & Fracture & 5 & DOD \\
\hline 2 & $\mathrm{M} / 29$ & Ilium & Mo & Ewing's sarcoma & T1-B, W+Plate & $\mathrm{K} 2$ & 11 & $E$ & & 14 & DOD \\
\hline 3 & $\mathrm{~F} / 54$ & Pelvis & M1 & $\begin{array}{l}\text { Metastatic tumour } \\
\text { (breast) }\end{array}$ & T1-A, W+Plate & K2 & 9 & $E$ & & 32 & DOD \\
\hline 4 & $\mathrm{M} / 52$ & Femur & M1 & $\begin{array}{l}\text { Metastatic tumour } \\
\text { (lung) }\end{array}$ & T1-B, W+IM & $\mathrm{K} 2$ & 7 & $\mathrm{E}$ & & 54 & NED \\
\hline 5 & $\mathrm{~F} / 13$ & Femur(d) & Mo & Osteosarcoma & T1-A, W+IM & K2 & 11 & G & & 51 & NED \\
\hline 6 & $\mathrm{~F} / 35$ & Humerus(p) & Mo & Osteosarcoma & T1-A, W+IM & $\mathrm{K} 2$ & 6 & $\mathrm{P}$ & Infection & 50 & $\mathrm{CDF}$ \\
\hline 7 & $F / 14$ & Radius & Mo & $\begin{array}{l}\text { Rhabdomyosar- } \\
\text { coma }\end{array}$ & T1-B, W+Plate & $\mathrm{K} 2$ & 10 & $\mathrm{~F}$ & & 41 & CDF \\
\hline 8 & $\mathrm{M} / 11$ & Femur & Mo & Ewing's sarcoma & T1-B, W+IM & $\mathrm{K} 2$ & 15 & $\mathrm{E}$ & & 38 & DOD \\
\hline 9 & $F / 68$ & Pelvis & Mo & Chondrosarcoma & T1-A, W+Plate & $(-)$ & - & $\mathrm{F}$ & Infection & 51 & CDF \\
\hline 10 & $\mathrm{M} / 14$ & Tibia(p) & M1 & Osteosarcoma & T1-A, M+IM & $\mathrm{K} 2$ & 9 & $E$ & & 39 & NED \\
\hline 11 & $\mathrm{M} / 24$ & Sacrum & Mo & Osteosarcoma & T2, M+Plate & $\mathrm{K} 2$ & 7 & $\mathrm{~F}$ & & 33 & AWD \\
\hline 12 & $F / 63$ & Femur & Mo & Leiomyosarcoma & T1-B, $M+I M+C$ & $\mathrm{~K} 2$ & 7 & $E$ & $\begin{array}{l}\text { Local } \\
\text { recurrence }\end{array}$ & 14 & DOD \\
\hline 13 & $\mathrm{M} / 38$ & Femur(d) & Mo & Osteosarcoma & T1-B, M+TKA & K2 & 5 & $\mathrm{E}$ & & 30 & CDF \\
\hline 14 & M18 & Humerus(p) & Mo & Osteosarcoma & T1-A, $M+I M+C$ & $\mathrm{~K} 2$ & 11 & G & & 30 & $\mathrm{CDF}$ \\
\hline 15 & $\mathrm{M} / 39$ & Femur(d) & Mo & Chondrosarcoma & T1-B, W+Plate+C & - & 6 & $E$ & & 34 & CDF \\
\hline 16 & $\mathrm{M} / 34$ & Femur(d) & M0 & $\begin{array}{l}\text { Malignant fibrous } \\
\text { histiocytoma }\end{array}$ & T3, $\quad W+I M+C$ & K2 & 7 & $E$ & & 19 & CDF \\
\hline 17 & $\mathrm{M} / 62$ & Femur(p) & M1 & $\begin{array}{l}\text { Metastatic tumour } \\
\text { (kidney) }\end{array}$ & T1-B, W+IM & $\mathrm{K} 2$ & 6 & $\mathrm{E}$ & & 37 & CDF \\
\hline 18 & $F / 16$ & Femur(d) & Mo & Ewing's sarcoma & T3, $\quad M+I M$ & $\mathrm{~K} 2$ & 6 & $\mathrm{E}$ & $\begin{array}{l}\text { Local } \\
\text { recurrence }\end{array}$ & 19 & $\mathrm{CDF}$ \\
\hline 19 & $\mathrm{M} / 56$ & Pelvis & Mo & Chondrosarcoma & T1-A, M+Plate & - & 6 & $\mathrm{P}$ & Infection & 12 & CDF \\
\hline 20 & $\mathrm{M} / 39$ & Tibia(p) & Mo & $\begin{array}{l}\text { Malignant fibrous } \\
\text { histiocytoma }\end{array}$ & $\mathrm{T} 1-\mathrm{A}, \mathrm{W}+\mathrm{IM}$ & $\mathrm{K} 2$ & 5 & $E$ & & 10 & CDF \\
\hline 21 & $\mathrm{~F} / 16$ & Tibia & Mo & Osteosarcoma & T1-B, W+IM & $\mathrm{K} 2$ & 5 & $E$ & & 13 & CDF \\
\hline 22 & $\mathrm{M} / 10$ & Femur(p) & Mo & Osteosarcoma & $\begin{array}{ll}\text { T3, } & \text { W+ } \\
& \text { Prosthesis }\end{array}$ & K2 & 4 & $E$ & & 10 & CDF \\
\hline 23 & $\mathrm{M} / 56$ & Humerus(p) & Mo & Chondrosarcoma & T1-A, M+IM & - & 5 & G & & 12 & CDF \\
\hline 24 & $\mathrm{M} / 15$ & $\operatorname{Tibia}(p)$ & Mo & Osteosarcoma & T1-A, W+IM & $\mathrm{K} 2$ & 2 & $E$ & & 30 & CDF \\
\hline 25 & $\mathrm{M} / 15$ & Femur(d) & Mo & Osteosarcoma & T1-A W+IM+C & K2 & 7 & $E$ & Fracture & 24 & CDF \\
\hline 26 & $F / 33$ & $\operatorname{Tibia}(p)$ & M1 & Ewing's sarcoma & $\begin{array}{ll}\text { T2, } & \text { W+ } \\
& \text { Prosthesis }\end{array}$ & K2 & 3 & $E$ & & 15 & CDF \\
\hline 27 & $\mathrm{~F} / 16$ & Femur(d) & Mo & Osteosarcoma & $\mathrm{T} 1-\mathrm{A}, \mathrm{W}+\mathrm{IM}+\mathrm{C}$ & K2 & 2 & $\mathrm{E}$ & & 12 & CDF \\
\hline 28 & $\mathrm{~F} / 13$ & Humerus(p) & M1 & Osteosarcoma & T1-A, M+Plate+B & K2 & 2 & $E$ & & 16 & DOD \\
\hline
\end{tabular}

* d, distal; p, proximal

† M0, no metastasis; M1, with metastasis

‡ T1, type-1 reconstruction; T2, type-2 reconstruction; T3, type-3 reconstruction; $M$, marginal excision; W, wide excision; C, cement; $B$, bone graft; IM, intramedullary nail; TKA, total knee arthroplasty

$\S$, excellent; G, good; F, fair; $P$, poor

I AWD, alive with disease; CDF, continuous disease free; DOD, died of disease; NED, no evidence of disease

ness of the bone and loss of the capacity for bone induction. ${ }^{21}$ We have developed a new method of treating autografts, based on in vitro and in vivo experiments, ${ }^{22}$ which uses the hypothermic effect of liquid nitrogen and which is a more useful recycling system.

\section{Patients and Methods}

We treated 28 patients, 17 men and 11 women with a mean age of 31.1 years (10 to 68) (Table I). Informed consent and a letter of acceptance had been obtained from all patients. The standard pre-operative examinations included a history, clinical examination, radiography including the chest, CT, technetium-99m bone scintigraphy, thallium-201 scintigraphy, MRI angiography and routine laboratory tests. The pre-operative K2 chemotherapy protocol which consists of five courses of intra-arterial cisplatin, caffeine, and doxorubicin at intervals of three weeks ${ }^{23}$ had been used in 24 patients with high-grade sarcoma. At operation the tumour was excised en bloc, the soft tissue was removed, the tumour curetted and the excised bone prepared for internal fixation or prosthetic replacement before freezing. The excised portion was frozen in liquid nitrogen for 20 minutes, thawed at room temperature for 15 minutes, thawed in distilled water for ten minutes and then replaced with reconstruction by an intramedullary nail, plate or composite use of a prosthetic replacement. Bone graft or cement was used for mechanical support when necessary. Intravenous chemotherapy was continued during the post-operative period using cisplatin, caffeine and doxorubicin and/or high-dose methotrexate combined with citrovorum factor and vincristine (three courses each). The affected limb was assessed according to the functional evaluation system of Enneking. ${ }^{24}$ 


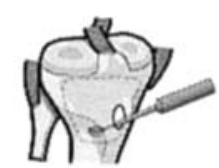

Tumour curettage

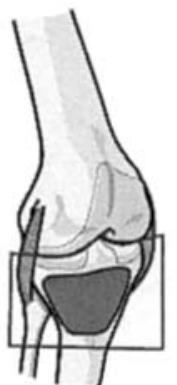

Intra-articular excision of proximal tibia

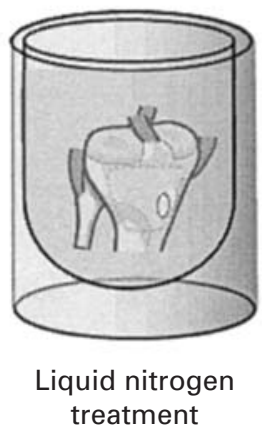

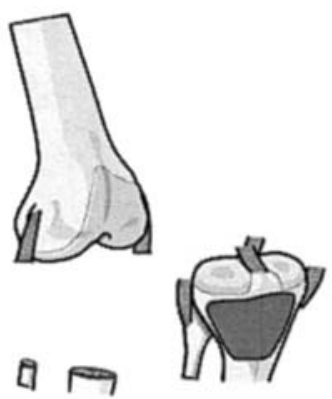

Tumour excision



Fig. 1

Diagrams showing type 1-A reconstruction.

\section{Results}

Details of the results are given in Table I. At the final follow-up, six patients had died at a mean of 19.8 months after the operation at 5,14, 32, 38, 14, and 16 months, respectively, while 21 remained free from disease at a mean follow-up of 28.1 months (10 to 54). One patient is alive with disease. Bony union was defined as complete cortical bridging in a long bone, or complete filling of the gap in the pelvis and sacrum. Bony union was seen at a mean of 6.7 months after the operation in 26 patients $(92.8 \%)$. Nonunion occurred in two. One of these died before bony union and in the other, the treated autograft was removed because it became infected before union. Function of the limb was rated as excellent in 20 patients $(71.4 \%)$, good in three $(10.7 \%)$, fair in three $(10.7 \%)$ and poor in two $(7.1 \%)$. Complications were encountered in seven patients, including three deep infections $(10.7 \%)$, two fractures $(7.1 \%)$, and two local recurrences $(7.1 \%)$, all of which were managed successfully. One case of infection was controlled by partial resection of the autograft, one was treated by removal of the autograft, and the third by debridement and irrigation. Local recurrence arising from soft tissue in two patients was treated by additional wide excision. Two frac- tures were managed by internal fixation. We classified the reconstruction method into three types; Type 1-A $(\mathrm{n}=14)$ was defined as intra-articular excision and reconstruction (Figs 1 and 2 ) and type $1-\mathrm{B}(\mathrm{n}=9)$ as intercalary excision and reconstruction. Type $2(n=2)$ constituted excision and reconstruction of the whole joint (Figs 3 to 5) and type 3 $(\mathrm{n}=3)$ comprised in situ freezing of the osteo-articular or intercalary lesion with or without osteotomy (Figs 6 and 7).

\section{Discussion}

Cryosurgery was first used in the management of bone tumours at the Memorial Sloan-Kettering Cancer Center in the United States in 1964 as a palliative procedure on a patient with a metastasis to the humerus from the lung. ${ }^{25,26}$ The use of liquid nitrogen for management of the primary lesion in osteosarcoma, was first described in 1984 by Marcove et $\mathrm{al}^{27}$ Repetitive freezing and thawing destroyed any tumour cells present at the margin of the curettage. The lesion was curetted, the cavity was frozen with liquid nitrogen, and then filled with cement. Immediate histological studies and those carried out at a second-look procedure showed no evidence of residual tumour. An en bloc excision of the tumour was not performed at that time. 



Fig. 2

Case 3. Figure $2 a$ - Radiograph of a 54-year-old woman with a right pelvic metastatic tumour from the breast. Figures $2 \mathrm{~b}$ and $2 \mathrm{c}-\mathrm{MRI}$ b) before and c) after chemotherapy. Figure $2 d$ - Internal hemipelvectomy was performed. The resected specimen was treated by liquid nitrogen. Figure $2 \mathrm{e}-$ Radiograph two years and four months after type 1-A reconstruction. All host-graft junctions are united.

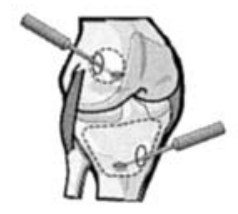

Tumour curettage

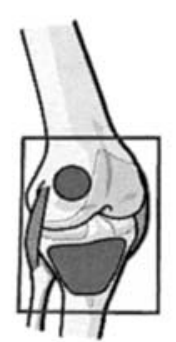

Whole joint excision of knee

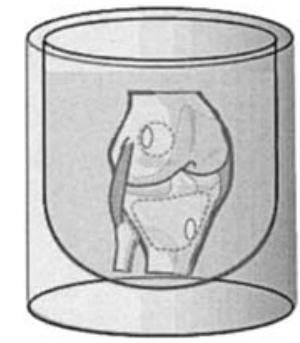

Liquid nitrogen treatment
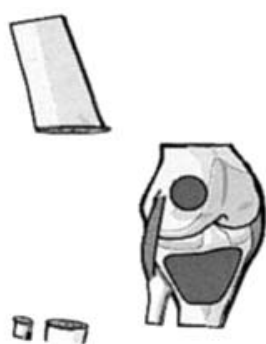

Tumour excision

Fig. 3

Diagrams showing the type-2 reconstruction

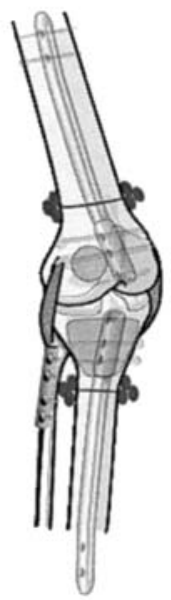

Osteosynthesis

Bone graft at host-graft junction 

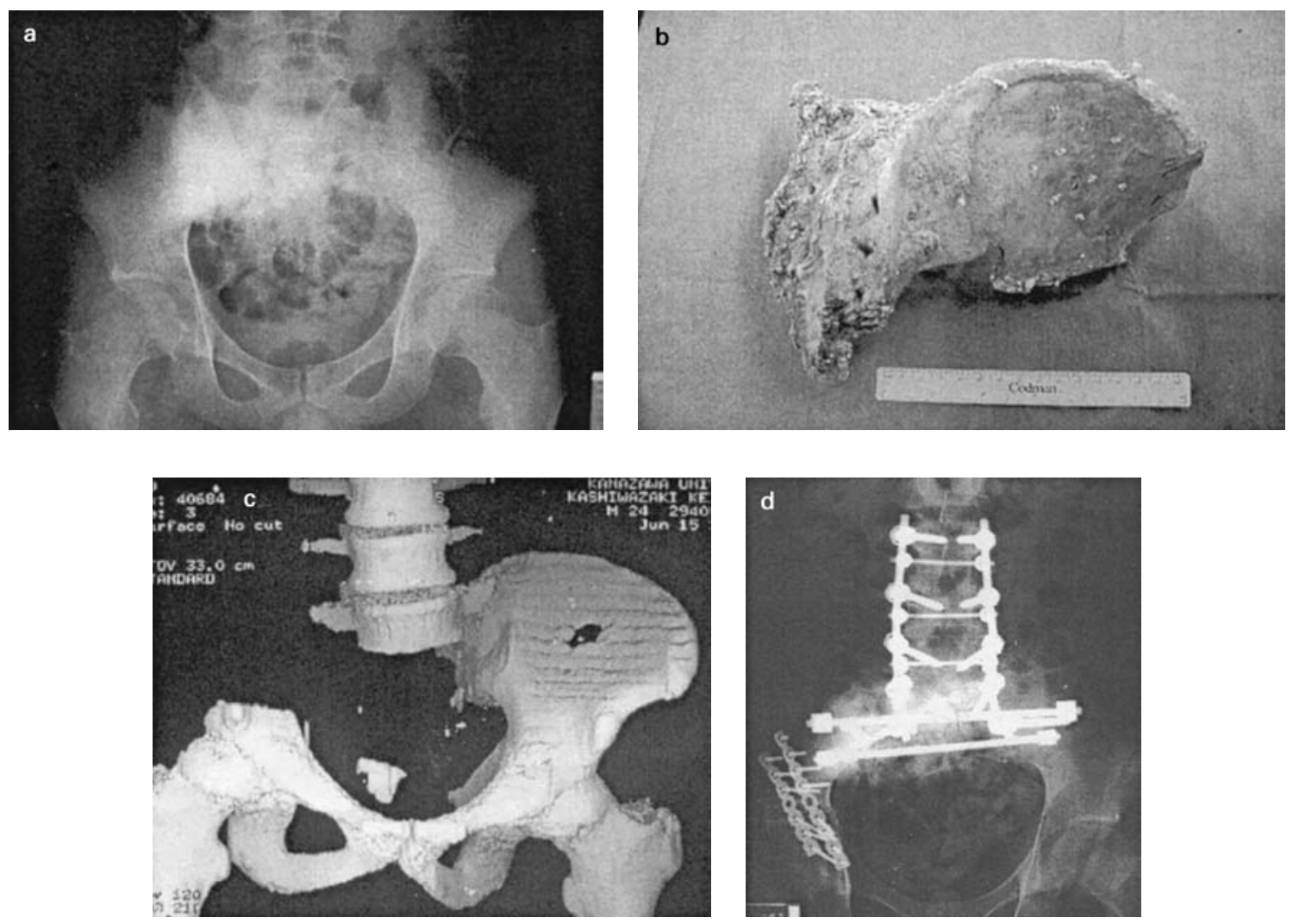

Fig. 4

Case 11. Figure $4 \mathrm{a}$ - Radiograph of a 24-year-old man with sacral osteosarcoma involving the iliac bone. Figure $4 \mathrm{~b}-\mathrm{Photograph}$ of a specimen excised after pre-operative chemotherapy, en bloc resection of the tumour, and treatment by liquid nitrogen. Figure 4c-3D-CT after excision of the tumour. Figure 4d - Radiograph after type-2 reconstruction. The patient can walk with crutches because the L5 roots have been preserved on both sides.

Cryosurgery destroys tissue selectively by the controlled use of alternating freezing and thawing. Another possible cause of cell death during cryosurgery is ischaemic infarction due to thrombosis of the microcirculation. ${ }^{28}$ Cryosurgery is usually used with adjunctive treatment such as chemotherapy, immunotherapy and conventional surgery. In our basic research, human osteosarcoma tissue, cultivated in athymic mice, was placed in a cavity created in the cortex of a metatarsal bone of a Holstein cow, the shape of which is similar to that of the human tibia. The metatarsal bone was then soaked in liquid nitrogen for 20 minutes. Afterwards, the tumour tissue was implanted into the back of athymic mice. No regrowth of tumour was seen. ${ }^{22}$ Cell structures are destroyed twice during freezing and thawing. Usually, tumour tissues and cell cultures need to be frozen with an anti-freezing agent such as dimethyl sulphoxide to grow again after being thawed. Our freezing procedure using one freezing cycle of 20 minutes was safe in this clinical study, although there were two patients with local recurrence. This occurred in the soft-tissue and probably represented satellite lesions from insufficient surgical resection.

The advantages of reconstruction using tumour-bearing massive frozen autograft treated by liquid nitrogen are sim- plicity, osteoinduction, osteoconduction, a short treatment time, preservation of the cartilage matrix, a perfect fit, sufficient biomechanical strength, no infection, no need for a bone bank, easy attachment of tendons and ligaments and desirable bone stock. The disadvantages are degeneration of the cartilage over time, the impossibility of histological analysis of the whole specimen and related complications similar to allograft implantation. Biomechanical testing showed no significant difference in compression strength between intact bone and the bone treated by liquid nitrogen, whereas in autoclaved bone the strength was decreased. ${ }^{22}$ The functional results are comparable with other methods of reconstruction, and once incorporated by the host, frozen autografts offer the advantage of incorporation as bone stock and with soft-tissue attachments, unlike metal implants. For osteo-induction the activities of proteins and enzymes are preserved in bones treated in liquid nitrogen. ${ }^{29,30}$ Freezing with liquid nitrogen is widely used to measure and analyse tumour and healthy tissues in biomedical research. Garusi et $\mathrm{al}^{31}$ found that bone graft frozen by liquid nitrogen acts as a normal graft in rats. Our results suggest that tumour-bearing autograft treated by liquid nitrogen is a simple and effective option for biological reconstructions. It is best used for osteoblastic tumours 

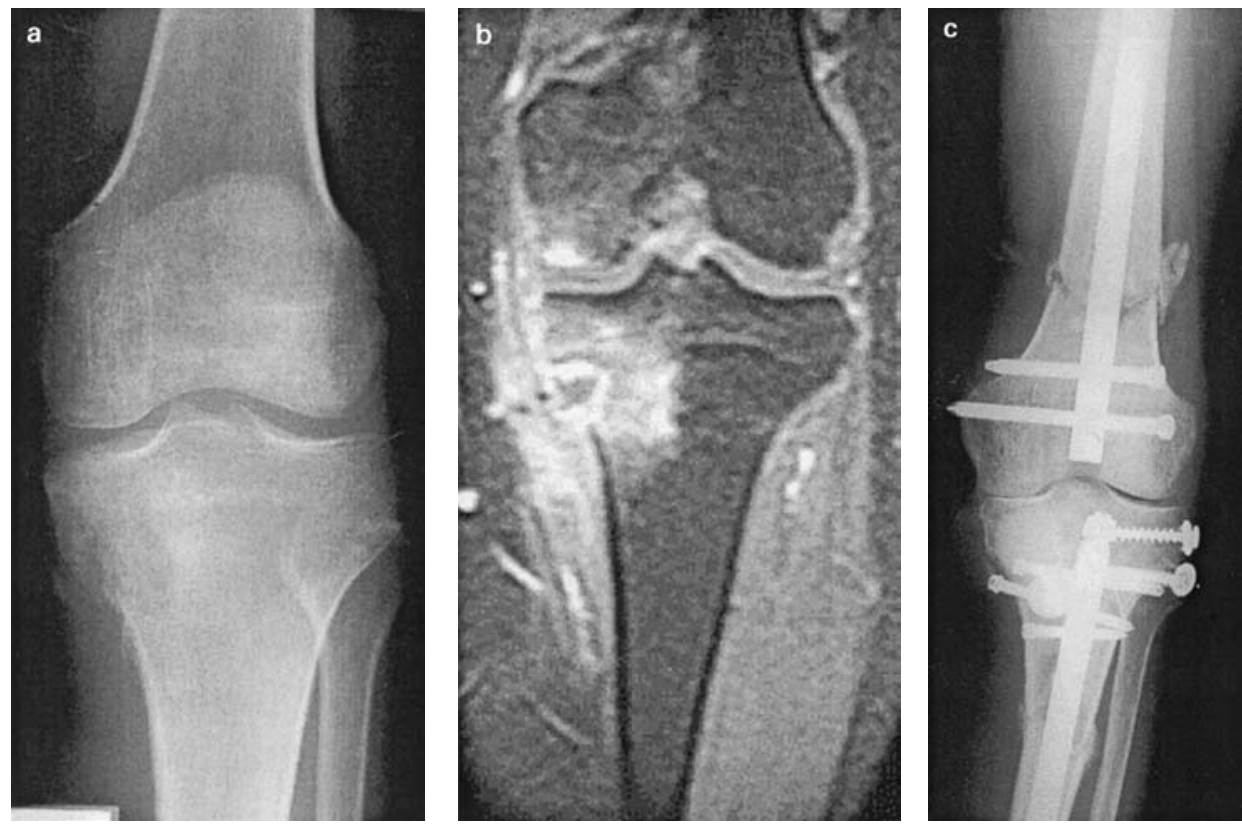

Fig. 5

Case 20. Figure 5a - Radiograph of a 39-year-old man with a malignant fibrous histiocytoma of the left proximal tibia involving the distal femur and left lower limb. Figure $5 b-$ MRI scan of the left lower limb. Figure 5c - Radiograph six months after internal fixation with intramedullary nails after en bloc excision of the knee (the distal femoral and proximal tibial lesions) which was treated by liquid nitrogen. The defect was supplemented with bone cement after curettage of the tumour.



Preservation of joint structure

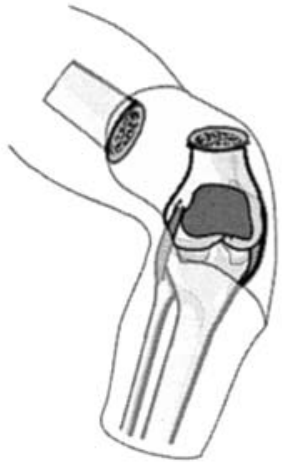

One-side osteotomy of distal femur
Fig. 6

Diagrams showing a type-3 reconstruction.



Isolation of the lesion Tumour curettage

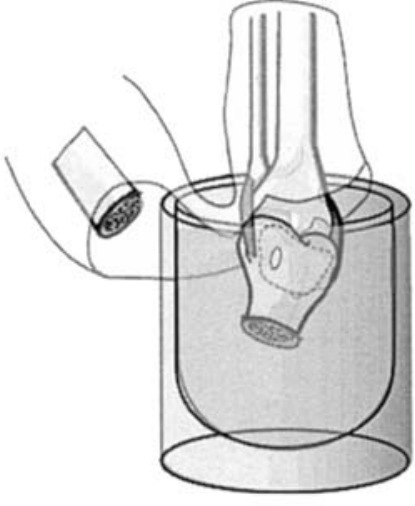

The leg rotated down Liquid nitrogen treatment

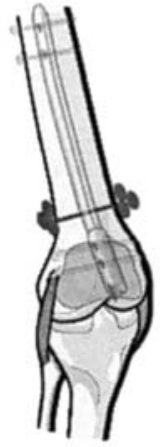

Osteosynthesis

Bone graft at host-graft junction 




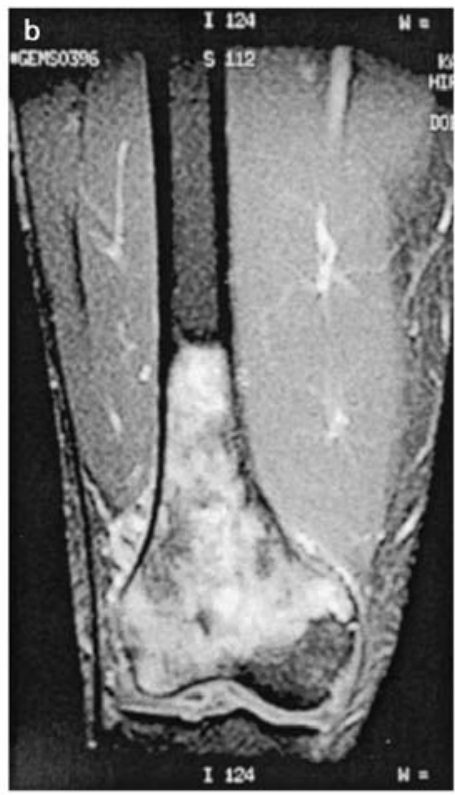

Fig. 7



Liquid nitrogen

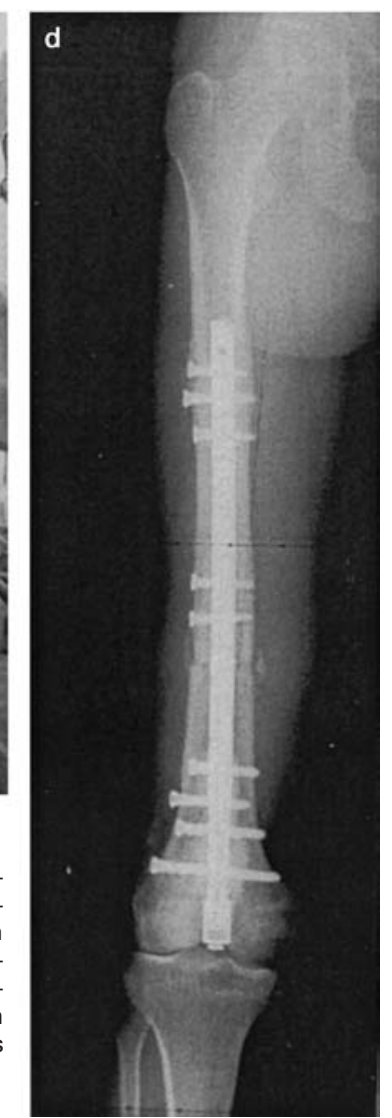

Case 16. Figures 7a and 7b-A 34-year-old man suffered from right knee pain because of a malignant fibrous histiocytoma of the right distal femur identified by a) radiography and b) MRI. Figure 7c - After pre-operative chemotherapy, the tumour was excised en bloc and the lesion was isolated with gauze and bandages to prevent contamination of tumour tissue in the exposed field. After curettage of the tumour, the distal femur was rotated down after diaphyseal osteotomy and soaked in liquid nitrogen as the continuity of knee was preserved. The distal femur and the artic ular surface of the proximal tibia were frozen. The defect after curettage of the tumour was supplemented with doxorubicin-impregnated bone cement. Type-3 reconstruction was performed. Figure 7d - Radiograph six months after surgery.

while prosthetic or allograft reconstruction should be used for osteolytic lesions.

The biomechanical strength of the frozen autograft may be weaker than that of an allograft depending on the extent of destruction by the tumour but it is an excellent option for pelvic and sacral lesions since allograft matching and reconstruction are very difficult in these patients. Type-3 reconstruction keeps the continuity of the joint intact, giving excellent stability and function since no important ligaments are sacrificed. We are developing equipment for freezing in situ to shorten the operating time, to maintain stable hypothermia and to reduce unnecessary damage to surrounding normal tissues. Type- 1 reconstruction requires the cutting of ligaments and the resutured tendon and ligament may not function well after freezing. Type- 2 reconstruction does not require resuture of joint structures, but does need excision of the joint. Therefore, type- 3 reconstruction is recommended if feasible.

Allografts used to reconstruct the bony defects after resection of a tumour offer many advantages, including reconstruction of the joint and incorporation of the graft to the host bone. However, the high incidence of complications makes the outcome unpredictable. ${ }^{32-34}$ Fracture is one of the common complications and is thought to result from revascularisation of the allograft cortex. Chemotherapy increases the rate of fracture at the allograft junction. ${ }^{35}$
This phenomenon may be due to an allogenic immune response. ${ }^{36}$ Other complications include graft resorption, recurrence, and nonunion. Frozen autografts contain autogenous proteins, growth factors and cytokines, and do not elicit an immune reaction. They have the advantages of early bony union and low risk of bone resorption although they may also have some complications similar to allografts, such as infection, fracture, nonunion, or failure of the graft resulting from the use of dead bone.

Another important aspect of treatment by liquid nitrogen is cryoimmunology. It is possible that tissue proteins released from the frozen lesions have antigenic properties which initiate an immune response directed against the tumour. There have been reports that metastatic tumours have regressed after freezing of the primary tumour. ${ }^{37,38}$ Cryoablation of tumour tissue induces inhibition of secondary growth of the tumour and causes release of cytokines. ${ }^{39,40}$ Therefore, tumour-bearing massive frozen autograft may play a role in reducing local recurrence and lung metastasis by its cryoimmunological function.

Cartilage frozen by liquid nitrogen will progress to osteoarthritic change in time as is seen in osteochondral allografts. ${ }^{41}$ Resurfacing total knee arthroplasty may be necessary for some patients in the future. Nevertheless, as bioengineering evolves, the ability to restore or repair cartilage may become a practical proposition. Recovery of 
chondrocytes has been observed in cryopreserved porcine articular cartilage by drilling a hole through the subchondral bone to the base of the cartilage. ${ }^{42}$

Reconstruction with tumour-bearing massive frozen autograft treated by liquid nitrogen in malignant bone and soft-tissue tumours is a simple and effective method of biological reconstruction. Long-term follow-up studies will provide more useful information and clarify the position.

No benefits in any form have been received or will be received from a commercial party related directly or indirectly to the subject of this article.

\section{References}

1. Unwin PS, Cannon SR, Grimer RJ, et al. Aseptic loosening in cemented custommade prosthetic replacements for bone tumours of the lower limb. J Bone Joint Surg [Br] 1996;78-B:5-13

2. Wodajo FM, Bickels J, Wittig J, Malawer M. Complex reconstruction in the management of extremity sarcomas. Curr Opin Oncol 2003;15:304-12.

3. Kawai A, Muschler GF, Lane JM, Otis JC, Healy JH. Prosthetic knee replacement after resection of a malignant tumor of the distal part of the femur: medium to long term results. J Bone Joint Surg [Am] 1998;80-A:636-47.

4. Kumar D, Grimer RJ, Abudu A, Carter SR, Tillman RM. Endoprosthetic replacement of the proximal humerus: long-term results. J Bone Joint Surg [Br] 2003;85-B: 717-22.

5. Schiller C, Windhager R, Fellinger EJ, et al. Extendable tumour endoprostheses for the leg in children. J Bone Joint Surg [Br] 1995;77-B:608-14.

6. Unwin PS, Walker PS. Extendible endoprostheses for the skeletally immature. Clin Orthop 1996;322:179-93.

7. Grimer RJ, Belthur M, Carter SR, Tillman RM, Cool P. Extendible replacements of the proximal tibia for bone tumours. J Bone Joint Surg [Br] 2000;82-B:255-60.

8. Tsuchiya H, Tomita K, Minematsu K, et al. Limb salvage using distraction osteogenesis. J Bone Joint Surg [Br] 1997;79-B:403-11.

9. Tsuchiya H, Abdel-Wanis ME, Sakurakichi K, Yamashiro T, Tomita K. Osteosarcoma around the knee: intraepiphyseal excision and biological reconstruction with distraction osteogenesis. J Bone Joint Surg [Br] 2002;84-B:1162-6.

10. Tsuchiya H, Abdel-Wanis ME, Kitano S, et al. The natural limb is the best: joint preservation and reconstruction by distraction osteogenesis for high-grade juxtaarticular osteosarcomas. Anticancer Res 2002;22:2373-6

11. Manfrini $\mathbf{M}$, Innocenti $\mathbf{M}$, Ceruso $\mathbf{M}$, Mercuri $\mathbf{M}$. Original biological reconstruc tion of the hip in a 4-year-old girl. Lancet 2003;361:140-2

12. Mankin HJ. The changes in major limb reconstruction as a result of the development of allografts. Chir Organi Mov 2003:88:101-13.

13. Gerrand $\mathbf{C H}$, Griffin AM, Davis AM, et al. Large segment allograft survival is improved with intramedullary cement. J Surg Oncol 2003;84:198-208.

14. Gitelis S, Piasecki P. Allograft prosthetic composite arthroplasty for osteosarcoma and other aggressive bone tumours. Clin Orthop 1991;270:197-201.

15. Yamamuro T, Kotoura Y. Intraoperative radiation therapy for osteosarcoma. Cance Treat Res 1993;62:177-83.

16. Tsuboyama T, Toguchida J, Kotoura Y, et al. Intra-operative radiation therapy for osteosarcoma in the extremities. Int Orthop 2000;24:202-7.

17. Lauritzen C, Alberius $P$, Santanelli F, et al. Repositioning of craniofacial tumorous bone after autoclaving. Scand J Plast Reconstr Surg Hand Surg 1991;25:161-5.

18. Thompson VP, Steggall CT. Chondrosarcoma of the proximal portion of the femur treated by resection and bone replacement: a six-year result. J Bone Joint Surg [Am] 1956;33-A:357-67
19. Ehara S, Nishida J, Shiraishi H, Tamakawa Y. Pasteurized intercalary autogenous bone graft: radiographic and scintigrahic features. Skeletal Radiol 2000;29: $335-9$.

20. Manabe J, Kawaguchi N, Matsumoto S. Pasteurized autogenous bone graft for reconstruction after resection of malignant bone and soft tissue tumors: imaging features. Semin Musculoskelet Radiol 2001;5:195-201.

21. Urist MR, Dawson E. Intertransverse process fusion with the aid of chemosterilized autolyzed antigen-extracted allogeneic (AAA) bone. Clin Orthop 1981;154:97-113.

22. Yamamoto N, Tsuchiya H, Tomita K. Effects of liquid nitrogen treatment on the proliferation of osteosarcoma and the biomechanical properties of normal bone. $J$ Orthop Sci 2003:8:374-80.

23. Tsuchiya H, Tomita K, Mori Y, Asada N, Yamamoto N. Marginal excision for osteosarcoma with caffeine assisted chemotherapy. Clin Orthop 1999;358:27-35.

24. Enneking WF. A system for functional evaluation of the surgical management of musculoskeletal tumors. In: Enneking WF, ed. Limb salvage in musculoskeletal oncology. New York, etc: Churchill-Livingstone, 1987:5-16

25. Marcove RC, Miller TR. The treatment of primary and metastatic localized bone tumors by cryosurgery. Surg Clin North Am 1969;49:421-30.

26. Marcove RC. A 17-year review of cryosurgery in the treatment of bone tumors. Clin Orthop 1982;163:231-4

27. Marcove RC, Zahr KA, Huvos AG, Ogihara W. Cryosurgery in osteogenic sarcoma: report of three cases. Comp Ther 1984;10:52-60.

28. Goldstein RS, Hess PW. Cryosurgical treatment of cancer. Vet Clin North Am 1977; 7:51-64.

29. Bunger MH, Langdahl BL, Anderson T, et al. Semiquantitative mRNA measure ments of osteoinductive growth factors in human iliac-crest bone: expression of LPM splice variants in human bone. Calcif Tissue Int 2003;73:446-54

30. Semevolos SA, Nixon AJ, Strassheim ML. Expression of bone morphogenetic protein-6 and -2 and a bone morphogenetic protein antagonist in horses with naturally acquired osteochondrosis. Am J Vet Res 2004;65:110-15

31. Garusi C, Calabrese L, Giugliano G, et al. Mandible reconstruction and autogenous frozen bone graft: experimental study on rats. Microsurgery 2001;21:131-4.

32. Brien EW, Terek RM, Healey JH, Lane JM. Allograft reconstruction after proxima tibial resection for bone tumours: an analysis of function and outcome comparing allograft and prosthetic reconstructions. Clin Orthop 1994;303:116-27.

33. Harrington KD. The use of hemipelvic allografts or autoclaved grafts for reconstruction after wide resections of malignant tumors of the pelvis. J Bone Joint Surg [Am] 1992;74-A:331-41

34. Donati D, Liddo $\mathbf{M}$, Zavatta $\mathbf{M}$, et al. Massive bone allograft reconstruction in highgrade osteosarcoma. Clin Orthop 2000;377:186-94

35. Hornicek FJ, Mnaymneh W, Lackman RD, Exner GU, Malinin TI. Limb salvage with osteoarticular allografts after resection of proximal tibia bone tumors. Clin Orthop 1998;352:179-86

36. Thompson RC, Pickvance EA, Garry D. Fractures in large-segmental allografts J Bone Joint Surg [Am] 1993;75-A:1663-73.

37. Drylie DM, Jordan WP, Robbins JB. Immunologic consequences of cryosurgery Invest Urol 1968;5:619-26.

38. Flocks RH, Nelson CM, Boatman DL. Perineal cryosurgery for prostatic carcinoma J Urol 1972;108:933-5.

39. Joosten JJ, Muijen GN, Wobbes T, Ruers TJ. In vivo destruction of tumor tissue by cryoblation can induce inhibition of secondary tumor growth: an experimental study. Cryobiology 2001;42:49-58

40. Joosten JJ, Muijen GN, Wobbes T, Ruers TJ. Cryosurgery of tumor tissue causes endotoxin tolerance through an inflammatory response. Anticancer Res 2003;23:427-32

41. DeGroot H 3rd, Mankin H. Total knee arthroplasty in patients who have massive osteoarticular allografts. Clin Orthop 2000;373:62-72.

42. Jomba NM, Anoop PC, McGann LE. Chondrocyte recovery in cryopreserved porcine articular cartilage after bone carrier alteration. Cryo Letters 2002;23:263-8. 